\title{
Construction of Army Equipment Support Transformation Demonstration System Based on Integration
}

\author{
Zhan-biao Zhao, Hui-qi Zhang, Chun-liang Chen, Ou Qi \\ Academy of Armored Force Engineering, Beijing, China \\ E-mail: xyzhq2002@163.com
}

\begin{abstract}
-to accelerate the construction of army equipment support, the concept of army equipment support transformation demonstration system is put up and the theory of demonstration system is concluded. By analyzing the equipment support transformation, the connotation is discussed and the transformation frame is given. By applying the system engineering meta-synthetic engineering office, the equipment support transformation demonstration system logical framework and the equipment support emulation model system is set up and the equipment support efficiency evaluation procedure is analyzed. The basis is offered for the subsequent army equipment support demonstration system.
\end{abstract}

Keywords- integration; equipment support transformation; demonstration system; construction

\section{INTRODUCTION}

Nowadays the amount factors are the main body of the equipment support in China. The preventive maintenance, the corrective maintenance and the overage spares make the life cycle cost, the support resources scale bigger and bigger, and make the equipment readiness level getting down. It can not fit the modern war. Transforming the equipment support model is the best choice for the equipment support development. It is also the requirement of performing the theme of the main line.

The top-level design and the objective program is the key of the equipment support transformation. How to demonstrate the equipment support design plan and the decision scheme is to solve. The system engineering integration method is adopted to construct the equipment support demonstration system. The scientific experiments and the Evaluation methods are supplied for the goal, the content, the method, the procedure and the technology roadmap of the equipment support transformation in this research.

\section{THE THEORETICAL BASIS OF THE DEMONSTRATION SYSTEM CONSTRUCTION}

\section{A. The Related Concepts of the Demonstration}

The demonstration comes from the advanced concept technology demonstration that put forward by the department of defense of American in 1994. It is based on one or several mature technology associate them together to demonstrate the new equipment support capability. The scale should fit the combat effectiveness and the system integrity of the demonstration. The advantage of the demonstration is to supply a way for transforming the technology obtained in the laboratory to the equipment support capability [1-2].

The equipment support demonstration system is to make a series of quantitative demonstration and assessment such as the demand analysis, program planning, Implementation strategy demonstration, Impact assessment by applying the system engineering theory. The scientific method is supplied to reduce the risk of the equipment support construction and exert the system entire efficiency. It is the first step to transform the technology into the support capacity.

The equipment support transformation system construction relates to the modern simulation technique such as the Meta-synthesis method, the artificial intelligence technology, the computer technology, the Virtual Reality Technology.

\section{B. Meta-synthesis Method}

The Meta-synthesis method is put forward by Xue-sen Qian. It is put forward to solve the problem in complex system such as social system, the geographical system and the military system. The essential of this method is to construct an intelligent man-machine combination system to advance the advantage of the integration, the collectivity and the intelligence by integrating the expert system, the data system, the information system and the computer system [3].

The Meta-synthesis method contains the science of mathematics, the science of system, the science of control, the intelligence and all kinds of information technology based on the computer technology such as the modeling simulation, the analysis and the optimization of system, as Fig. 1 shows.

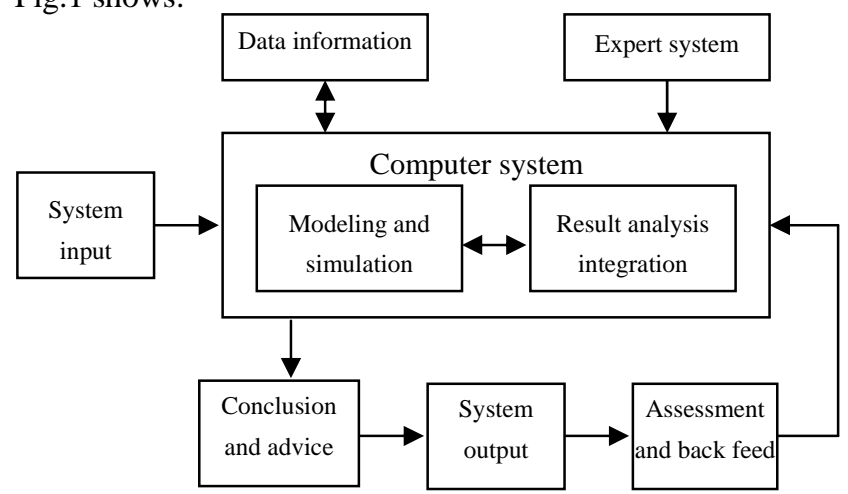

Figure 1. Meta-synthesis man-machine system scheme

Meta-synthetic Engineering Office system (Hall for Work Shop of Meta-synthetic Engineering, HWSME) is the development of integrated approach. There are three systems 
in this method: the machine system, the expert system, the knowledge system that based on the integration and fusion of modern high-tech. the expert system and the machine system is the carrier of the knowledge, as Fig. 2 shows.

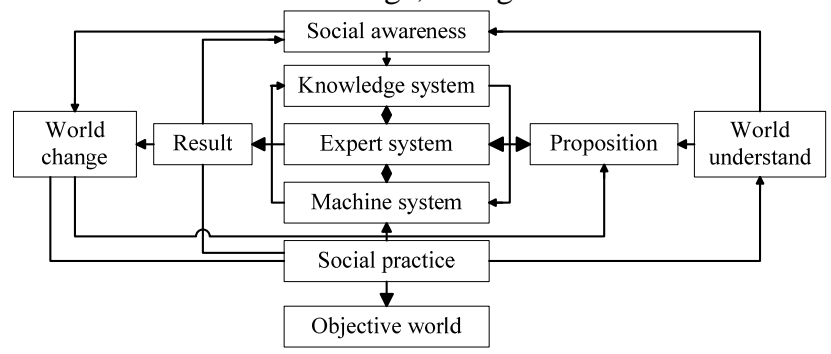

Figure 2. Meta-synthetic engineering office frame

\section{THE TRANSFORMATION ANALYSIS OF EQUIPMENT SUPPORT}

The equipment support transformation is to apply the information technologies to equipment support area, improve the equipment theory, preparation system, technical means, and combat readiness training by using the system engineering and the modeling simulation method, and constructs the equipment support system based on the information system to accelerate the equipment support ability generating scheme transformation and achieve the transformation from mechanization to Information.

The equipment transformation is system engineering. Its frame contains the agent floor, the surroundings floor, the context floor [4]. It refers to many factors. Putting forward the equipment support by applying the system engineering analysis methods and introducing multi-view expression, as Fig. 3 shows.

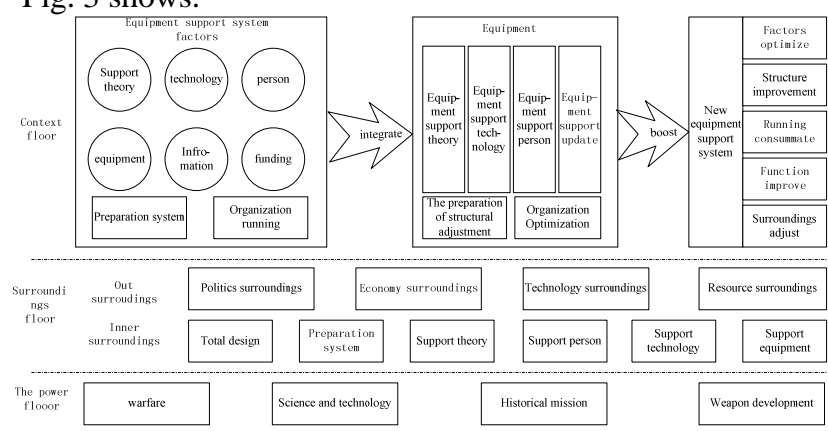

Figure 3. The equipment support transformation frame

The agent floor is the hauling power of the equipment support in Fig. 3. It is also the indispensable condition of the analysis of the transformation surroundings and the context; the surroundings floor provide the basis for the influence factors putting forward and makes the transformation context putting forward more pertinences; the context floor confirms the work track and the work approach and accelerate the construction of the new equipment support system.

The equipment system is the substance basis and is the research object of the equipment support. Their structures reflect the correlation and the function dividing of the equipment support subsystem. The organization, the structure, the running mode, the function and the surroundings are shown in Fig. 4.

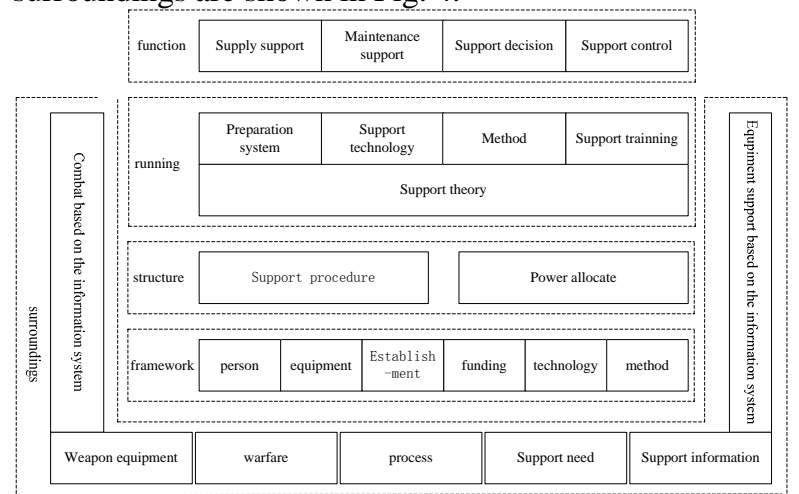

Figure 4. The organization, the structure, the running mode, the function and the surroundings of the equipment support

The equipment support contains the person, the equipment, the funding, the technology and the method. In the factors, the person is the main body, the equipment is the matter basis, the technology is the propellant and the funding is the power [5]. The person plays the dynamic role in the process. It is the basis to improve the equipment support ability. It is also the key factor of the equipment support transformation.

The equipment support structure reflects the division of the subsystem and the function. It is the basis for the equipment support implement. The allocation and the procedure is its key factor.

The run of the equipment support system is the peoplecentered mode based on the equipment support structure. It is the basis of the equipment support play. The essential of the equipment support is the transformation of the equipment support. It contains the research and implement of the support theory, the adjustment of the preparation system, the applying of the support technology and the method and the training of the person. The run of the equipment is the key part of the equipment support ability improvement. The main part of the equipment support transformation is to improve the equipment support running mode.

The function of the equipment support system contains the supply support, maintenance Support, the decision support and the operation support. Under the condition that the support resource can be utilized effectively, to deploy the support theory, the preparation system, the support technology, the support method and the support train according to certain power allocation and support procedure can makes the equipment support system more effective.

\section{THE CONSTRUCTION OF THE EQUIPMENT SUPPORT DEMONSTRATION}

\section{A. Design of Demonstration System}

The demonstration system logic frame structure is given according to the equipment support transformation analysis and the implement policy research, as Fig. 5 shows. 


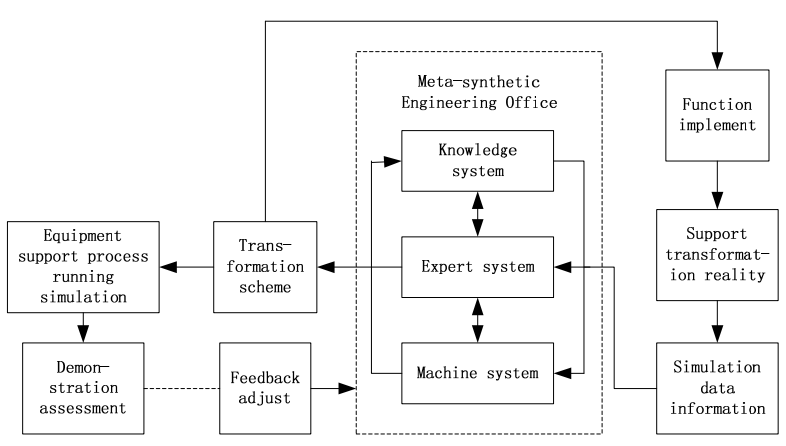

Figure 5. The equipment support transformation demonstration system logic structure

Simulate the real factors to get the simulation information, apply the Meta-synthetic Engineering Office method to give the equipment support transformation scheme and simulate the support process running to assess the transformation scheme in Fig.5. The dashed line means the transformation scheme is not perfect and it needs the feed to the Meta-synthetic Engineering Office to adjust. Simulate and assess the demonstration again until the transformation scheme meets the requirement. Then apply the transformation scheme to the equipment support reality.

The simulation of the equipment support transformation and the simulation of the equipment running is the basis of the system running in the demonstration system, as Fig. 6 shows.

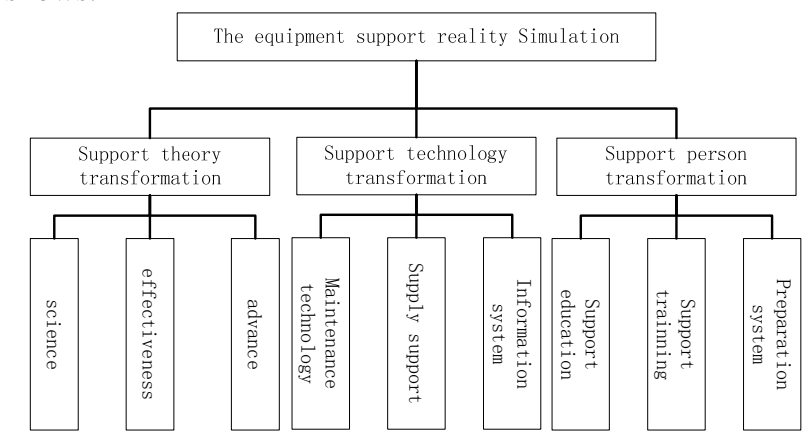

Figure 6. The equipment support transformation reality simulation factors

\section{B. Equipment Support Simulation}

The equipment support simulation is the process that utilizes the computer and nerwork platform and uses all kinds of equipment support model to simulate the equipment support surroundings, the running process, the activities and the support result. The equipment support simulation system is constructured according to the simulation system design principle based on the analysis of the equipment support simulation, as Fig.7 shows.

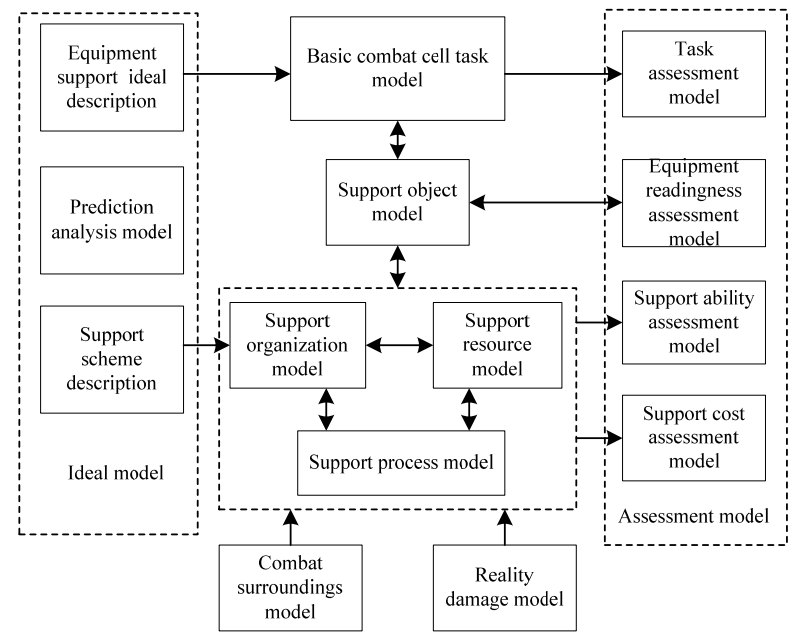

Figure 7. The equipment support simulation system

The ideal model describes the equipment support simulation running process on the total floor and gives the simulation logic description in Fig.7. According to the ideal model, the basic task model of the combat cell can be set up and the support scheme, the support organization model, the support resource model and the support process model can be preset. The structure, the resolving power, the running mode of the equipment simulation is different. It needs different kind support of the mode to realize the simulation on form.

The equipment support always adopts the equipment cell oriented polymerization floor model. But the basic combat cell especially the support cell always be constructed based on the weapon floor. It refers to the system, the granularity of the component floor model.

The equipment support simulation contains the discrete event simulation and the consecutive events simulation, such as the basic combat cell in the process of task execution can adopt the simulation based on the consecutive events.

The equipment support process is always constructed in the form of the process simulation. The equipment support relate to the process that the support reality alter and cooperate. The support reality adjust its own behavior by the alter function. The support reality and the alter function cooperate to complete the task. The new method is needed to deal with the new problem, such as the agent simulation.

\section{Equipment Support Effectiveness Assessment}

\section{1) The indispensable condition of assessment}

- Set up the equipment support ability assessment index system. To divide the equipment support ability into single index that can be described by number is needed to quantify the equipment support effectiveness. The factors that influences the equipment effectiveness contains the command and control factors, the intensive maintenance factors, the supply factors, the combat protect factors, the organization and coordination factors and the support guard factors. 
- $\quad$ Set up the equipment effectiveness assessment model. Tell apart the factors that can not be quantified easily such as equipment task and support surroundings and the factors can be quantified by reasonable algorism. Calculate the support need and the support ability by using different method.

- Set up the equipment support effectiveness assessment basic database. The equipment effectiveness always has 3 kinds: the standard database, the weighting database, the unit basic information database.

- $\quad$ Set up the equipment support effectiveness analysis module. The equipment support system is constituted of the maintenance support, the equipment and ammo supply, the equipment control. The effectiveness always be calculated by the single index and combine them together. Thus every specialty should set up a special analysis modular to gather and register the data according to certain process.

2) The assessment basic flow

- Confirm the assessment object. Confirm the assessment object and select the assessment index of support effectiveness according to the equipment support goal.

- Select the assessment system and the assessment modular. The equipment support effectiveness is always calculated by the equipment support corresponding assistant computer.

- Confirm the constrain condition. The equipment support involves a large area. Different combat mode, different equipment composing, different combat surroundings condition, different combat object influence the equipment composing, the organization, the spatial and temporal distribution, the combat loss differently.

- Confirm the assessment calculate flow and adjust the inner parameter. The equipment support effectiveness assessment is very complex. It needs to choose the calculate flow, check and adjust the assessment parameter before call for the calculate modular.

- Input and adjust the equipment support decision data and achieve the assessment calculate. When the support decision change, the related data must be adjusted together to reach a trustiness conclusion. After input the equipment support data, the equipment support effectiveness can be analyzed by the computer.

- Compare the calculate result with the assessment conclusion and adjust constrain condition and the equipment support decision data and get the assessment conclusion. Then choose the best scheme. 8.

The equipment support effectiveness flow is show in Fig.

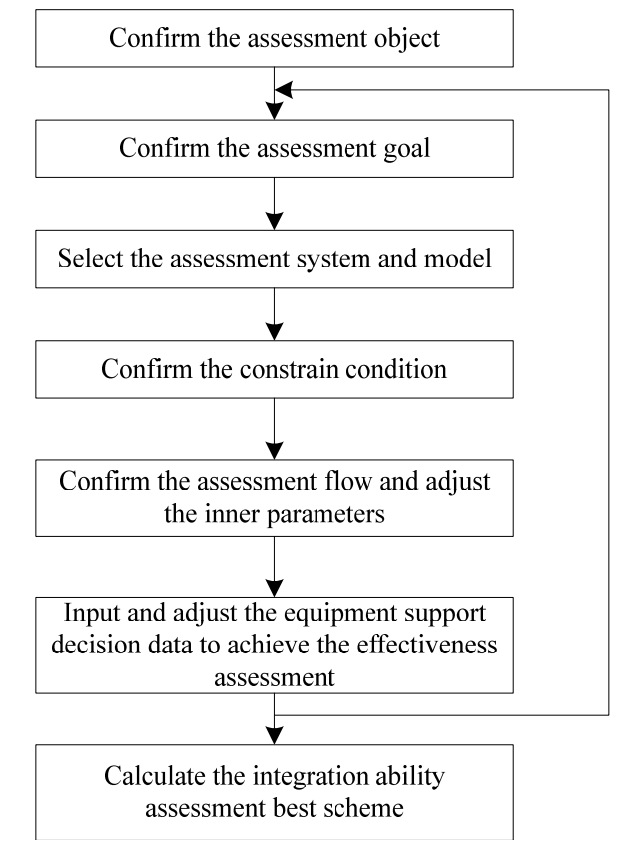

Figure 8. The support effectiveness assessment basic flow

\section{CONCLUSIONS}

Do the equipment support transformation research, constructure the integral equipment support system is the require of the new revolution in military affairs. It can improve the equipment support effecively, reduce the equipment Life Cycle Cost, save the support resource. The demonstration system construction theory and method basis are expound and the equipment support transformation system is analyzed. In order to construct the equipment support transformation demonstration, the demonstration total frame is designed. The equipment support simulation and the effectiveness are analyzed and described. The research ideal and technology method are provided for the equipment support total design and goal plan.

\section{REFERENCES:}

[1] Phelps. ACTDs: Management Plans as Predictors of Transition [R]. Naval Postgraduate School, Monterey, CA,2007.

[2] Ma Chunyan.. The previous notion technology demonstration and combat experiment commence [J]. The air equipment. 2005, (01):8-9.

[3] Hu Xiaofeng, Luo Pi, Si Guangya [M]. Beijing: National Defence Industry Press, 2005.

[4] Bai Sijun. Modern item control [M]. Beijing: the machine industry press, 2004.

[5] Sun Baotan, Jia Xisheng, Cheng Zonghua.. Study on equipment support process modeling and simulation in wartime[J]. Command control \& simulation. 2012, (02):97-101. 